\title{
Evaluation of the Operational Effectiveness of Grading Diagnosis and Treatment System in China
}

\author{
Wang Wanli* \\ School of Economics and Management \\ Jiangxi University of Science and Technology \\ Gan Zhou,341000,China \\ E-mail:ww10207666@163.com
}

\author{
Zeng Guohua \\ School of Economics and Management \\ Jiangxi University of Science and Technology \\ Gan Zhou,341000,China \\ E-mail:zensoyou@163.com
}

\begin{abstract}
To analyze the effect of hierarchical diagnosis and treatment in different levels of medical institutions in China, and to provide scientific basis for improving the hierarchical diagnosis and treatment system in China. The DEA model and Malmquist index model were used to analyze the operation effect of grading diagnosis and treatment of medical institutions in China from 2009 to 2017. The level of hierarchical diagnosis and treatment efficiency of medical and health institutions in China is low. The large hospitals in the eastern region and grass-roots hospitals in the whole country are on the low side. There is a situation of blind expansion and surplus of health technicians in large hospitals. The comprehensive efficiency of grass-roots hospitals is slightly higher than that of large hospitals. The insufficient number of beds and health technicians leads to the deterioration of their efficiency. China's hierarchical diagnosis and treatment operation effect is not good, large hospital emergency sinking is insufficient. Technical progress is slow. The basic hospital facilities and lack of talent is the main reason restricting the efficiency of grading diagnosis and treatment. Speeding up online diagnosis and intelligent diagnosis layout to crack general practitioner(GP) supply bottleneck, building a close medical association and realizing the rational distribution of medical resources.
\end{abstract}

Keywords-grading diagnosis and treatment; effect assessment; DEA-Malmquist $\square$

\section{INTRODUCTION}

Establishing a grading diagnosis and treatment system of "primary diagnosis, two-way referral, rapid division and treatment, and up-and-down linkage", rationalizing medical order, rationally arranging medical resources, and promoting equalization of medical services are important contents for deepening the reform of the medical and health system. It is also the main goal and important task of deepening medical reform during the 13th Five-Year Plan period. Since China first proposed the establishment of grading diagnosis and treatment system in 2009, Governments at all levels have also issued a series of policies to improve the service capacity of grass-roots medical institutions, promote family doctors'contracting services, promote the informatization of medical services, reform the way of medical insurance payment, and strengthen the management of chronic diseases. The timely evaluation of the implementation of grading diagnosis and treatment is an important starting point for summarizing the effectiveness of work and promoting the grading of medical treatment.
In recent years, many scholars began to pay attention to the effect evaluation of graded diagnosis. Based on the "structure-process-result" model, domestic researchers initially formed a theoretical framework model for evaluating the effect of the implementation of graded diagnosis and treatment ${ }^{[1]}$. The initial effect evaluation was only a descriptive analysis. Through different levels of hospital medical expenses, number of patients, per capita hospitalization costs, the new rural cooperative medical insurance fund flows in two directions. The effect of graded diagnosis was evaluated by doctors and multi-point practitioners [2]. With the deepening of the research, DEA method began to attract attention in the field of graded diagnosis and treatment, but the results were not satisfactory. From 2009 to 2015, only three DEAs were effective in 16 municipal public hospitals in Chongqing ${ }^{[3]}$. Another study for national hospitals found that in 2012, the per capita number of doctors in 31 provinces and municipalities in China and the actual openness of the DEA method were found. The number of beds is negatively correlated with the overall efficiency of hospitals, and the investment in large-scale equipment and infrastructure has not completely turned to positive benefits, but has produced a reverse hindrance effect [4]. In addition, from the point of view of a single type of hospital, the use of super-efficiency DEA to analyze the government-run hospitals of traditional Chinese medicine and find out the classification diagnosis and treatment. The present situation of implementation is still not satisfactory ${ }^{[5]}$.

Overall, the existing research has carried out a more in-depth analysis of the operational effects of the grading diagnosis and treatment system in China, but it has the following shortcomings:

(1) More indicators are used to analyze the efficiency of hospital or medical resource utilization, rather than grading diagnosis and treatment. Research on the effect of system operation;

(2) DEA analysis of multipurpose cross-sectional data, lack of time series analysis;

(3) Differences in evaluation of grading diagnosis and treatment of hospitals of different levels were not considered.

In view of this, this paper starts from the starting point and requirements of the grading diagnosis and treatment system, scientifically selects the operational effect evaluation index, applies DEA and Malmquist index model to investigate the effect of grading diagnosis and treatment of different types of 
medical institutions in China during 2009-2017, and proposes countermeasures.

\section{IMPLEMENTATION OF THE GRADING DIAGNOSIS AND TREATMENT SYSTEM IN CHINA}

\section{A. The outpatient and emergency visits is concentrated in} large hospitals

Table 1 summarizes the outpatient situation of different types of medical institutions in China during 2009-2017. The data comes from the "China Health Economics Statistical Yearbook" over the years.

In 2009-2017, outpatient and emergency visits in China's major hospitals increased from 1.875 billion to 3.363 billion, with a total increase of 1.488 billion, with an annual growth rate of $7.61 \%$, of which the average growth rate in $2011-2012$ reached $12.31 \%$; The outpatient visits increased from 2.469 billion to the current 3.29 billion, with a total increase of 821 million, with an annual growth rate of only $3.65 \%$.

TABLE I. CHANGES IN THE EVALUATION INDICATORS OF MEDICAL INSTITUTIONS IN 2009-2017

\begin{tabular}{|c|c|c|c|c|c|c|c|c|}
\hline \multirow{2}{*}{ Year } & \multicolumn{3}{|c|}{ outpatient visits (million people) } & \multicolumn{3}{|c|}{ Number of admissions (million) } & \multicolumn{2}{|c|}{$\begin{array}{c}\text { Outpatient } \\
\text { hospitalization ratio }\end{array}$} \\
\hline & $\begin{array}{c}\text { Large } \\
\text { hospitals }\end{array}$ & $\begin{array}{l}\text { Primary } \\
\text { hospitals }\end{array}$ & $\begin{array}{c}\text { Primary } \\
\text { hospital } \\
\text { share }\end{array}$ & $\begin{array}{c}\text { Large } \\
\text { hospitals }\end{array}$ & $\begin{array}{l}\text { Primary } \\
\text { hospitals }\end{array}$ & $\begin{array}{c}\text { Primary } \\
\text { hospital } \\
\text { share }\end{array}$ & $\begin{array}{c}\text { Large } \\
\text { hospitals }\end{array}$ & $\begin{array}{l}\text { Primary } \\
\text { hospitals }\end{array}$ \\
\hline 2009 & 1875.4 & 2469.2 & 56.83 & 84.86 & 39.70 & 31.87 & 22.1 & 62.2 \\
\hline 2010 & 1991.8 & 2642.6 & 57.02 & 95.30 & 39.50 & 29.30 & 20.9 & 66.9 \\
\hline 2011 & 2210.9 & 2820.8 & 56.06 & 107.33 & 37.76 & 26.03 & 20.6 & 74.7 \\
\hline 2012 & 2483.1 & 3088.1 & 55.43 & 127.34 & 42.54 & 25.04 & 19.5 & 72.6 \\
\hline 2013 & 2679 & 3275.9 & 55.01 & 140.26 & 42.99 & 23.46 & 19.1 & 76.2 \\
\hline 2014 & 2902.9 & 3313.1 & 53.30 & 153.59 & 40.95 & 21.05 & 18.9 & 80.9 \\
\hline 2015 & 3016.6 & 3282.6 & 52.11 & 160.46 & 40.38 & 20.10 & 18.8 & 81.3 \\
\hline 2016 & 3197.1 & 3277.2 & 50.62 & 175.66 & 41.64 & 19.16 & 18.2 & 78.7 \\
\hline 2017 & 3363 & 3290.4 & 49.45 & 188.93 & 44.53 & 19.07 & 17.8 & 73.9 \\
\hline
\end{tabular}

From the horizontal composition of the emergency annual growth rate of emergency patients in primary hospitals department, the proportion of outpatient visits in primary hospitals has gradually decreased from $56.83 \%$ in 2009 to is lower than that of large hospitals, and the change rate is large. The highest growth rate in 2012 is $9.48 \%$, and the lowest $49.45 \%$ in 2017 . In terms of vertical trend, except for 2010 , the

in 2015 is only $-0.92 \%$. As shown in Fig. 1 .

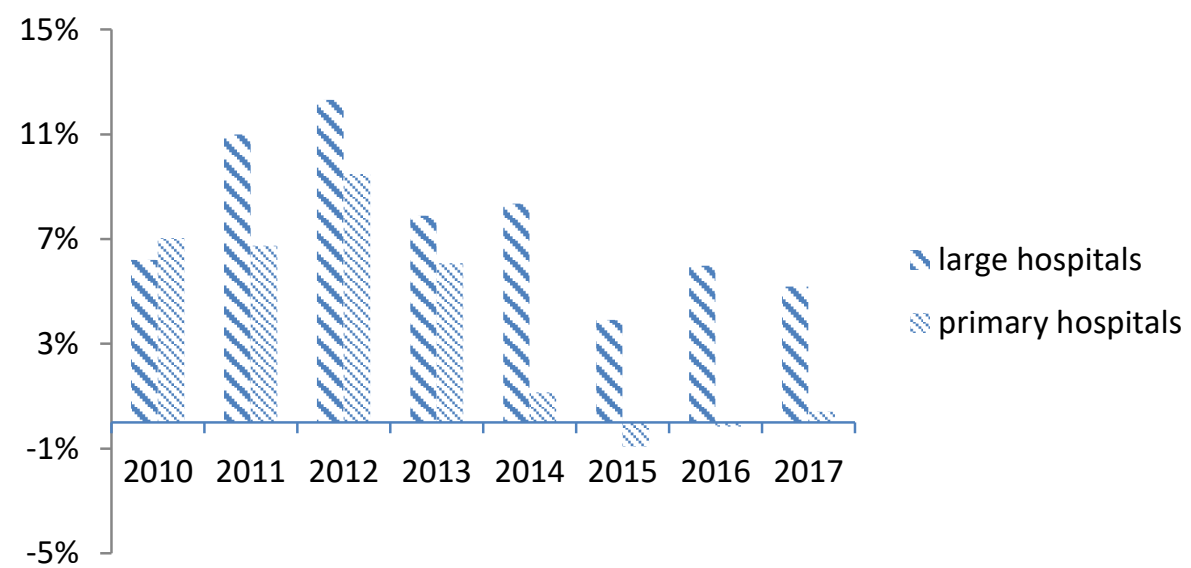

Fig. 1. Change in the growth rate of number of outpatient visits in 2009-2017

\section{B. Descriptive analysis of relevant output indicators}

From the point of view of admissions, the number of admissions to major hospitals in China increased from 849.9 million to 189 million in 2009-2017, with an annual growth rate of $10.52 \%$; the number of admissions to primary hospitals increased from 0.397 billion to 0.445 billion now, with an annual growth rate of only $1.45 \%$. 
The outpatient hospitalization ratio of large hospitals showed a slow downward trend from 2009 to 2017. The outpatient hospitalization ratio of large hospitals decreased from 22.1 to 17.8 , with a decline of $19.5 \%$. There were significant differences in the annual change range. In 2010, the outpatient hospitalization ratio of large hospitals reached the maximum, that is $-5.4 \%$, and in 2015 , the minimum, that is $0.53 \%$. From 62.2 to 73.9 , the growth rate reached $18.8 \%$. Negative growth occurred in 2012, 2016 and 2017, with an average annual growth rate of $2.34 \%$.
Generally speaking, the outpatient visits of medical institutions in China is increasing obviously, but the development trend of medical structure at different levels is quite different. Compared with large hospitals, the growth of outpatient visits in primary hospitals is slow, especially after 2014. The proportion of outpatient visits in primary hospitals is declining. This shows that in the period of 2009-2017, the outpatient and emergency patients in our country are still concentrated in large hospitals, and the primary care required by the grading diagnosis and treatment system has not really been realized.

TABLE II. INDICATORS OF DIAGNOSIS AND TREATMENT AT DIFFERENT LEVELS IN 2017

\begin{tabular}{|c|c|c|c|c|}
\hline \multirow{2}{*}{ Province } & \multicolumn{2}{|c|}{ Outpatient visits (millions) } & \multicolumn{2}{|c|}{ Outpatient hospitalization ratio } \\
\hline & Second and third level hospitals & Primary hospitals & Second and third level hospitals & Primary hospitals \\
\hline Beijing & 145.888 & 3.220 & 46.4 & 107.3 \\
\hline Tianjin & 70.964 & 15.445 & 47.8 & 171.6 \\
\hline Hebei & 137.431 & 193.944 & 14.5 & 110.2 \\
\hline Shanxi & 54.322 & 43.179 & 14.1 & 74.4 \\
\hline Inner Mongolia & 48.549 & 25.887 & 15.9 & 55.1 \\
\hline Liaoning & 98.375 & 49.162 & 15.0 & 70.2 \\
\hline Jilin & 50.461 & 26.522 & 14.5 & 94.7 \\
\hline Heilongjiang & 64.646 & 26.569 & 12.6 & 32.4 \\
\hline Shanghai & 152.834 & 6.941 & 41.5 & 99.2 \\
\hline Jiangsu & 252.586 & 180.858 & 22.3 & 71.2 \\
\hline Zhejiang & 274.291 & 136.742 & 32.1 & 333.5 \\
\hline Anhui & 104.975 & 119.720 & 13.3 & 63.3 \\
\hline Fujian & 98.064 & 69.422 & 22.0 & 84.7 \\
\hline Jiangxi & 65.946 & 110.932 & 12.6 & 45.7 \\
\hline Shandong & 218.243 & 276.660 & 15.5 & 87.8 \\
\hline Henan & 183.901 & 306.607 & 14.1 & 89.4 \\
\hline Hubei & 132.365 & 145.839 & 14.7 & 45.7 \\
\hline Hunan & 98.879 & 103.630 & 10.0 & 25.1 \\
\hline Guangdong & 366.925 & 186.296 & 28.2 & 92.7 \\
\hline Guangxi & 95.727 & 93.404 & 16.7 & 37.4 \\
\hline Hainan & 18.576 & 18.980 & 19.1 & 172.5 \\
\hline Chongqing & 66.336 & 47.193 & 14.3 & 23.5 \\
\hline Sichuan & 180.336 & 183.918 & 14.5 & 35.4 \\
\hline Guizhou & 61.311 & 60.828 & 10.7 & 45.4 \\
\hline Yunnan & 101.099 & 104.447 & 14.3 & 67.4 \\
\hline Tibet & 6.022 & 5.542 & 21.5 & 138.5 \\
\hline Shaanxi & 84.333 & 70.399 & 13.4 & 73.3 \\
\hline Gansu & 44.562 & 53.276 & 13.2 & 66.6 \\
\hline Qinghai & 11.743 & 6.610 & 14.2 & 47.2 \\
\hline Ningxia & 18.968 & 11.425 & 17.9 & 190.4 \\
\hline Xinjiang & 54.370 & 29.119 & 12.5 & 28.3 \\
\hline
\end{tabular}

Regionally, in 2017, the outpatient visits in central and western hospitals is relatively low. Tibets, Qinghai and Ningxia were the last three in the west, Hainan, Tianjin and Fujian were the last three in the east, Jilin, Shanxi and Heilongiiang were the last three in the middle, while there was no significant difference in the number of primary hospitals, Shandong, Hebei and Guangdong were the first three in the east. The top three in the central region are Henan, Hubei and Anhui, and the top three in the western region are Sichuan, Yunnan and Guangxi.

The outpatient hospitalization ratio of major hospitals in the eastern region is higher than that in the western region and the smallest in the central region, with Hunan having the lowest outpatient hospitalization ratio; the outpatient hospitalization ratio of primary hospitals is higher than that of other provinces except Ningxia, Tibet and Shaanxi in the western region, Jilin in the central region, Henan and Shanxi in the eastern

region, and the outpatient hospitalization ratio is the highest in the three provinces. Tianjin, Beijing and Shanghai are the municipalities directly under the Central Government.

\section{VARIABLE SELECTION AND METHOD}

\section{A. Variables selection}

The starting point of the grading diagnosis and treatment system is to form the first-level diagnosis, two-way referral, rapid division and treatment, and the operation mechanism of the upper and lower linkages, to achieve the first diagnosis at 
the grassroots level, intractable diseases to large hospitals, so that the treatment of different diseases by different levels of medical institutions is classified. The core of the diagnosis and treatment. In areas where the grading diagnosis and treatment system is functioning well, outpatients in large hospitals should be reasonably sunk to the community, and inpatients should be rationally diverted to rehabilitation care institutions ${ }^{[6]}$. From this perspective, the grading diagnosis and treatment of China can be evaluated according to the outpatient condition of the primary hospital, the actual two-way referral ratio, the theoretical referral ratio, and the rehabilitation ratio of the chronic disease primary hospital.

However, China has not established a standardized two-way referral system, and there is no relevant statistics. The evaluation of two-way referral at the macro-regional level is currently difficult to achieve. Similarly, there is no relevant statistics on the rehabilitation of chronic diseases in primary hospitals. Therefore, the evaluation of outpatient scale in primary hospitals is a good choice for measuring the evaluation of regional grading diagnosis and treatment.

Under the requirements of the grading diagnosis and treatment system, the primary hospitals mainly undertake the first consultation, so the outpatient share and outpatient hospitalization ratio are selected as the output indicators; while the large hospitals are more responsible for the diagnosis and treatment of intractable diseases. The lower the outpatient share and outpatient hospitalization ratio, the better the operation effect of grading diagnosis and treatment, so the output indicators are selected as 1/outpatient share and 1/outpatient hospitalization ratio. The input indicators include the number of institutions, the number of beds, the number of health technicians, and doctors are responsible for daily visits.

Therefore, outpatient share and outpatient hospitalization ratio are used as indicators to judge the effect of grading diagnosis and treatment:

1) the outpatient share of primary hospital = outpatient visits of primary hospital / (outpatient visits of primary hospital + large hospital outpatient visits) ;

2)the outpatient hospitalization ratio of primary hospital $=$ outpatient visits of primary hospital / number of admissions of primary hospital;

3)the outpatient share of large hospital = outpatient visits of large hospital / (outpatient visits of primary hospital + large hospital outpatient visits);

4) the outpatient hospitalization ratio of large hospital = outpatient visits of large hospital / number of admissions of large hospital;

According to the requirements of the grading diagnosis and treatment, the lower the outpatient hospitalization ratio and the outpatient share of the large hospital, the higher the outpatient service ratio and the grassroots outpatient share of the primary hospital, the better the grading diagnosis and treatment effect.

The selection of indicators for large hospitals and primary hospitals is shown in Table 3.

TABLE III. NATIONAL GRADING DIAGNOSIS AND TREATMENT EVALUATION INDEX SYSTEM

\begin{tabular}{|l|l|l|}
\hline \multirow{4}{*}{ indicators } & \multicolumn{1}{|c|}{ large hospitals } & \multicolumn{1}{c|}{ primary hospitals } \\
\hline \multirow{4}{*}{$\begin{array}{l}\text { Input } \\
\text { indicator }\end{array}$} & the number of institutions & the number of institutions \\
\cline { 2 - 3 } & the number of beds & the number of beds \\
\cline { 2 - 3 } & the number of health technicians & the number of health technicians \\
\cline { 2 - 3 } & doctors are responsible for daily visits. & $\begin{array}{l}\text { doctors are responsible for daily } \\
\text { visits. }\end{array}$ \\
\hline \multirow{2}{*}{$\begin{array}{l}\text { Output } \\
\text { indicator }\end{array}$} & $1 /$ outpatient share & outpatient share \\
\cline { 2 - 3 } & $1 /$ outpatient hospitalization ratio & outpatient hospitalization ratio \\
\hline
\end{tabular}

\section{B.Method}

Using the data of medical institutions in 31 provinces and cities in China from 2009 to 2017 to evaluate the operational efficiency of the hierarchical diagnosis and treatment system of large hospitals and primary hospitals in China. The data comes from the China Health Statistics Yearbook 2010-2018.

(1) Establishment of input-oriented DEA-BCC model to evaluate the efficacy of grading diagnosis in medical institutions nationwide from 2009 to 2017 ;

(2) To analyze the effect rate of grading diagnosis of 31 DMUs in 2009 and 2017 respectively, including comprehensive efficiency, pure technical efficiency, scale efficiency and comparative analysis of provinces with input redundancy and output deficit.

(3) The Malmquist index analysis method is used to dynamically measure the efficiency and technological progress in different periods, and objectively measure the technical

efficiency changes, technological changes and total factor changes of the national medical and health institutions. 


\section{EMPIRICAL ANALYSIS}

A. Static Evaluation of the Efficiency of Grading Diagnosis in Medical Institutions from 2009-2017

Since the implementation of grading diagnosis and treatment, the grading diagnosis and treatment system in major hospitals in China has been running smoothly. The overall efficiency has been gradually optimized before 2011, rising from 0.688 to 0.712 . The input-output efficiency has steadily increased in 2011 and reached 0.737 in 2017, surpassing the previous peak. See Fig. 2.
At the regional level, there are different comprehensive efficiencies in the eastern, central and Western regions. The comprehensive efficiencies of large hospitals in the central and

western regions are higher, while those in the eastern regions are lower, which indicates that the implementation effect of grading diagnosis and treatment in regions with high economic development is not ideal. This is contrary to people's intuitive judgment, grading diagnosis and treatment in the central and western regions is higher. Although there was a slight microwave motion, both of them remained near 0.8 .

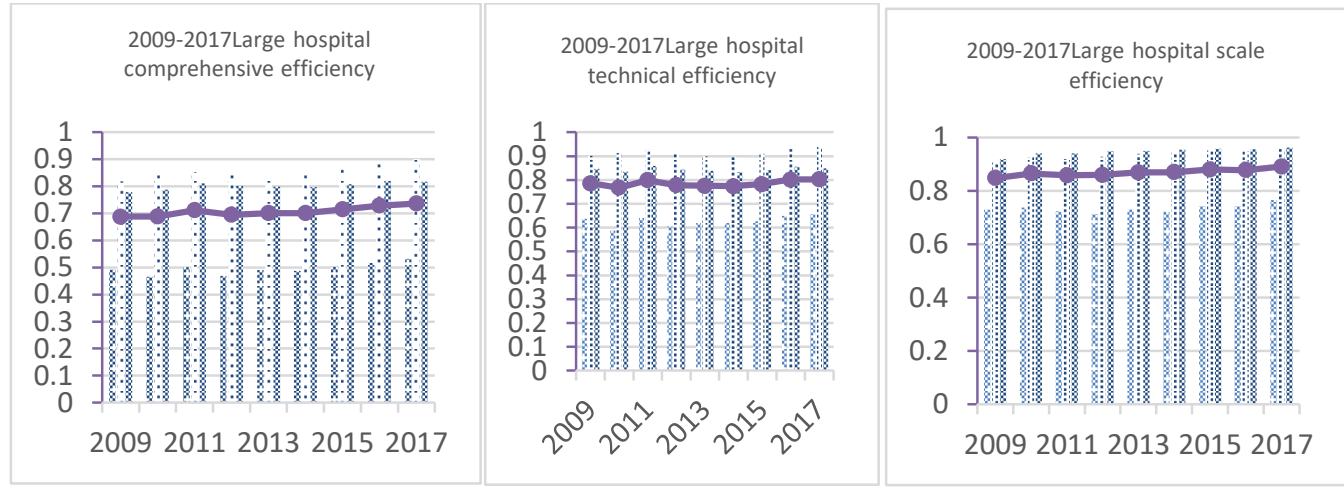

Figu. 2 DEA efficiency of China's large hospitals grading diagnosis and treatment operation in 2009-2017

The curative effect rate of grading diagnosis in national primary hospitals declined in 2012, rebounded in 2014, and then slowly declined. The root cause lies in the backward grass-roots health resources and inadequate service capacity of medical and health institutions. The implementation effect of grading diagnosis and treatment in our country is increasing slowly, while the basic level hospitals, though with a large base, have a very high level. Good market for grading diagnosis and treatment, but the effect of grading diagnosis has a further downward trend, which is not consistent with the situation that existing research found that the allocation of primary health resources and the utilization of health services in China are on the rise ${ }^{[7]}$. The reason is that on the one hand, the efficiency of grading diagnosis and treatment is measured in this paper, and the selected indicators focus on passing through the door. On the other hand, the allocation of primary health resources and the utilization rate of health services can not fully reflect the operational efficiency of primary hospitals only from the perspective of simple growth. At the regional level, the comprehensive efficiency of primary hospitals is the lowest in the east, the second in the West and the highest in the middle, which is the result of grading diagnosis in large hospitals. Distribution is consistent. See Fig. 3.

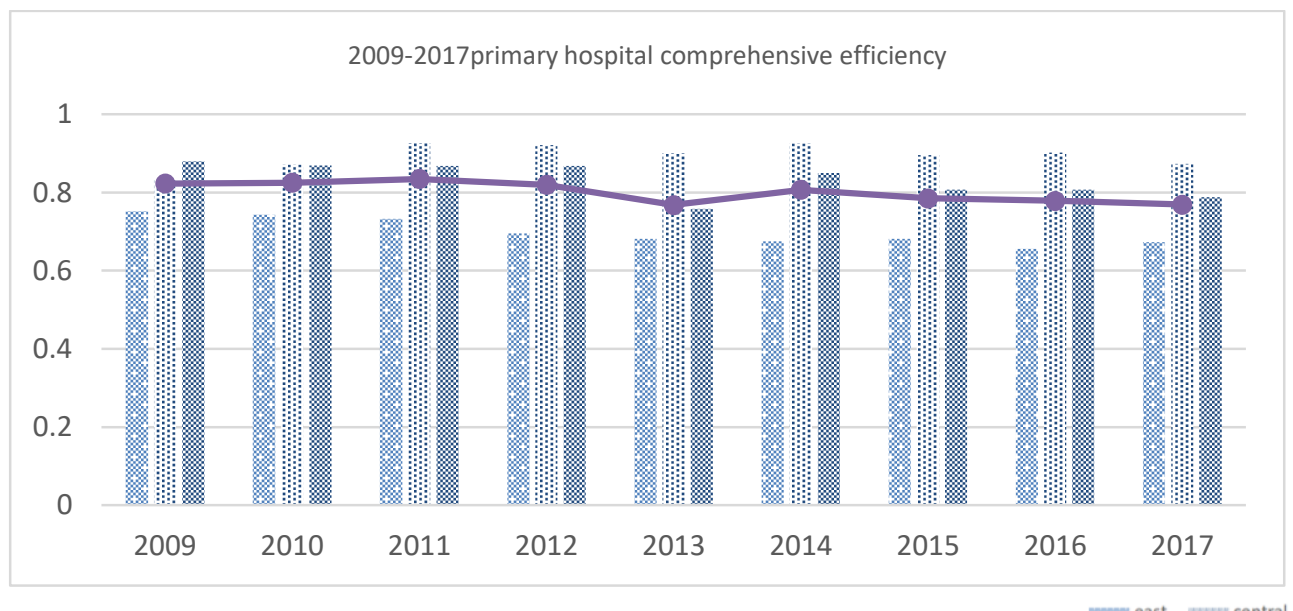

Fig. 3 Comprehensive efficiency of grading diagnosis and treatment of primary hospitals from 2009 to 2017 
Generally speaking, China's grading diagnosis and treatment is low, and the efficiency of large hospitals shows a slow growth trend. The large hospitals in eastern region have considerable room for improvement. The comprehensive efficiency of primary hospitals varies greatly, especially around 2013. The rapid rise and fall of the efficiency is noticeable. It shows that the basic level hospitals are unstable. Although the comprehensive efficiency is relatively high, they still can not meet the needs of the vast majority of the people. The great enrichment of materials will inevitably stimulate the people, especially the grassroots people's demand for high-quality health. Our country's per capita medical resources are low. The core factors of evaluating the curative effect of grading diagnosis in large hospitals and primary hospitals reasonably, guiding the rational allocation of medical resources and maximizing the benefits of talents, can make medical resources benefit more people.

\section{B. Analysis of the rate of grading diagnosis of medical institutions in various provinces and cities in 2017}

1)In order to further analyze regional differences and understand the effectiveness of the implementation of grading diagnosis and treatment, DEA analysis was conducted on the efficiency of grading diagnosis and treatment in 31 provinces and cities in 2017. See Table IV.

TABLE IV. EFFICIENCY OF GRADING DIAGNOSIS IN MEDICAL AND HEALTH INSTITUTIONS OF PROVINCES AND MUNICIPALITIES IN 2017

\begin{tabular}{|c|c|c|c|c|c|c|c|c|}
\hline \multirow[b]{2}{*}{ Province } & \multicolumn{4}{|c|}{ Large hospitals grading diagnosis rate } & \multicolumn{4}{|c|}{ Grading rate of primary hospitals } \\
\hline & Effch & Techch & Pech & $\begin{array}{c}\text { Scale } \\
\text { remuneration }\end{array}$ & Effch & Techch & Pech & $\begin{array}{c}\text { Scale } \\
\text { remuneration }\end{array}$ \\
\hline Beijing & 0.285 & 0.555 & 0.514 & irs & 0.471 & 0.83 & 0.568 & irs \\
\hline Tianjin & 0.337 & 0.513 & 0.657 & irs & 0.721 & 0.8 & 0.901 & irs \\
\hline Hebei & 1 & 1 & 1 & - & 1 & 1 & 1 & - \\
\hline Shanxi & 1 & 1 & 1 & - & 0.971 & 1 & 0.971 & irs \\
\hline $\begin{array}{l}\text { Inner } \\
\text { Mongolia }\end{array}$ & 0.809 & 0.944 & 0.857 & irs & 0.929 & 1 & 0.929 & irs \\
\hline Liaoning & 0.687 & 0.848 & 0.81 & irs & 0.564 & 0.669 & 0.844 & irs \\
\hline Jilin & 0.869 & 0.98 & 0.887 & irs & 0.894 & 1 & 0.894 & irs \\
\hline Heilongjiang & 0.933 & 0.978 & 0.954 & irs & 0.81 & 1 & 0.81 & irs \\
\hline Shanghai & 0.215 & 0.408 & 0.526 & irs & 0.533 & 0.964 & 0.553 & irs \\
\hline Jiangsu & 0.426 & 0.533 & 0.799 & irs & 0.45 & 0.473 & 0.953 & irs \\
\hline Zhejiang & 0.297 & 0.439 & 0.678 & irs & 1 & 1 & 1 & - \\
\hline Anhui & 0.765 & 0.815 & 0.938 & irs & 0.802 & 0.803 & 0.999 & drs \\
\hline Fujian & 0.505 & 0.608 & 0.83 & irs & 0.538 & 0.561 & 0.958 & irs \\
\hline Jiangxi & 1 & 1 & 1 & - & 1 & 1 & 1 & - \\
\hline Shandong & 0.845 & 0.853 & 0.99 & irs & 0.784 & 0.793 & 0.989 & drs \\
\hline Henan & 0.962 & 0.967 & 0.995 & drs & 0.74 & 1 & 0.74 & drs \\
\hline Hubei & 0.67 & 0.756 & 0.886 & irs & 0.77 & 0.77 & 0.999 & drs \\
\hline Hunan & 1 & 1 & 1 & - & 1 & 1 & 1 & - \\
\hline Guangdong & 0.309 & 0.459 & 0.673 & irs & 0.344 & 0.396 & 0.868 & irs \\
\hline Guangxi & 0.652 & 0.702 & 0.929 & irs & 0.655 & 0.655 & 1 & - \\
\hline Hainan & 0.946 & 1 & 0.946 & drs & 1 & 1 & 1 & - \\
\hline Chongqing & 0.664 & 0.702 & 0.946 & irs & 0.775 & 0.813 & 0.953 & irs \\
\hline Sichuan & 0.63 & 0.65 & 0.971 & irs & 0.54 & 0.543 & 0.994 & irs \\
\hline Guizhou & 0.985 & 1 & 0.985 & drs & 0.876 & 0.876 & 1 & - \\
\hline Yunnan & 0.631 & 0.661 & 0.955 & irs & 0.639 & 0.639 & 0.999 & drs \\
\hline Tibet & 1 & 1 & 1 & - & 1 & 1 & 1 & - \\
\hline Shaanxi & 0.764 & 0.79 & 0.967 & irs & 0.769 & 0.785 & 0.979 & irs \\
\hline
\end{tabular}




\begin{tabular}{|l|l|l|l|l|l|l|l|l|} 
Gansu & 0.951 & 1 & 0.951 & drs & 0.976 & 0.983 & 0.993 & drs \\
\hline Qinghai & 1 & 1 & 1 & - & 0.777 & 1 & 0.777 & irs \\
\hline Ningxia & 0.821 & 0.832 & 0.987 & irs & 1 & 1 & 1 & - \\
\hline Xinjiang & 0.894 & 0.896 & 0.997 & drs & 0.524 & 0.65 & 0.806 & irs \\
\hline mean & 0.737 & 0.803 & 0.891 & & 0.769 & 0.839 & 0.919 &
\end{tabular}

Note: drs: diminishing returns to scale; -: unchanged returns to scale; irs: increasing returns to scale, comprehensive efficiency is the technical efficiency without considering returns to scale; pure technical efficiency is the technical efficiency when considering returns to scale; scale efficiency is the scale efficiency when considering returns to scale; scale returns are divided into increasing returns to scale and increasing returns to scale. Decreasing returns to scale and unchanged returns to scale.

From Table 4, it can be seen that the comprehensive efficiency, pure technical efficiency and scale efficiency of large hospitals have reached 1 in the provinces: 1 in the east (Hebei), 2 in the middle (Shanxi, Jiangxi and Hunan), and 2 in the west (Tibet and Qinghai).

In addition, although the comprehensive efficiency and scale efficiency of Gansu, Guizhou and Hainan are not 1, but the pure technical efficiency is 1 , which achieves the weak efficiency of DEA. Scale efficiency is the key factor hindering the effectiveness of comprehensive efficiency. Scale efficiency reflects the management level in depth. It shows that the main problem of the low operation of grading diagnosis and treatment in large hospitals in these areas is the insufficient management level. There are also problems of excessive expansion of large hospitals and unbalanced distribution of large hospitals, which reduce medical accessibility. Pure technical efficiency is counter-productive. Reflecting the output level of innovation under certain conditions. It shows that the efficiency of hospitals at all levels has been greatly improved at the technical level after the implementation of the grading diagnosis and treatment policy. It is imperative to improve the utilization of medical resources in large hospitals in three regions and rationally allocate spatial layout.

For the primary hospitals, the average comprehensive efficiency value of the 31 provinces is 0.769 , and the comprehensive efficiency range is $0.344 \sim 1$, which has large regional differences[8]. Among them, 9 provinces with comprehensive efficiency (comprehensive efficiency $=1$ ) accounted for $29.03 \%$, mainly concentrated in the western region; 13 provinces with pure technical efficiency (pure technical efficiency = 1), accounting for $41.94 \%$, these 13 provinces If the input factors are fully utilized at the current scale and their output reaches a maximum, DEA can be effective. Among the non-DEA-producing provinces, 16 provinces are increasing in scale, indicating that the proportion of input increase is less than the increase in output. The current scale is small, and increasing the input can bring a larger proportion of output. For a long time in China, the "siphon effect" of large hospitals has caused the uneven distribution of medical resources, and more and more high-quality medical resources are concentrated in large hospitals. At the same time, a large number of medical treatments can be visited in grassroots communities. The patient was "siphoned" to the large hospitals, and the inverted triangle structure was prominent [9].

\section{Dynamic analysis based on Malmquist}

The Malmquist index analysis is carried out on the input and output data of each region from 2009 to 2017, and the TFP index and its decomposition of the past years and regions are obtained.

TABLE V. DYNAMIC EVALUATION OF OPERATIONAL EFFICIENCY OF NATIONAL MEDICAL AND HEALTH INSTITUTIONS IN $2009-2017$

\begin{tabular}{|c|ccccc|ccccc|}
\hline & \multicolumn{5}{|c|}{ Large hospitals } & \multicolumn{3}{c|}{ Primary hospitals } \\
\hline Year & Effch & Techch & Pech & Sech & TFP & Effch & Techch & Pech & Sech & TFP \\
\hline 2010 & 0.983 & 1.023 & 0.965 & 1.019 & 1.005 & 0.993 & 1.031 & 0.999 & 0.994 & 1.024 \\
2011 & 1.043 & 0.920 & 1.054 & 0.990 & 0.959 & 1.018 & 0.976 & 1.009 & 1.009 & 0.994 \\
2012 & 0.967 & 1.001 & 0.968 & 0.999 & 0.968 & 0.978 & 0.989 & 0.994 & 0.985 & 0.968 \\
2013 & 1.015 & 0.958 & 0.998 & 1.017 & 0.973 & 0.921 & 1.360 & 0.954 & 0.966 & 1.253 \\
2014 & 0.997 & 0.940 & 0.998 & 0.999 & 0.937 & 1.059 & 0.685 & 1.011 & 1.047 & 0.726 \\
2015 & 1.029 & 0.956 & 1.015 & 1.014 & 0.984 & 0.971 & 1.056 & 0.954 & 1.018 & 1.026 \\
2016 & 1.029 & 0.947 & 1.030 & 0.999 & 0.974 & 0.993 & 0.923 & 1.025 & 0.969 & 0.917 \\
2017 & 1.019 & 0.960 & 1.001 & 1.018 & 0.978 & 0.993 & 0.963 & 0.991 & 1.002 & 0.956 \\
mean & 1.010 & 0.963 & 1.003 & 1.007 & 0.972 & 0.990 & 0.983 & 0.992 & 0.998 & 0.973 \\
\hline
\end{tabular}


Table 5 shows that in the period of 2009-2017, the productivity index of major hospitals in China is less than 1, which is 2010-2017. Only the productivity index of 2009-2010 is more than 1, and the level of total factor productivity is increasing. According to TFPch $=$ Effch $\times$ TEch, the trend of technological change is basically consistent with that of total factor productivity. The change of technological efficiency is less than 1 in 2009-2010, 2011-2012 and 2013-2014. During these three years, the technological efficiency has been decreasing continuously, that is, the actual output has been decreasing continuously while the input factors remain unchanged. This means that the ability of the unit to be evaluated to achieve maximum output is declining.

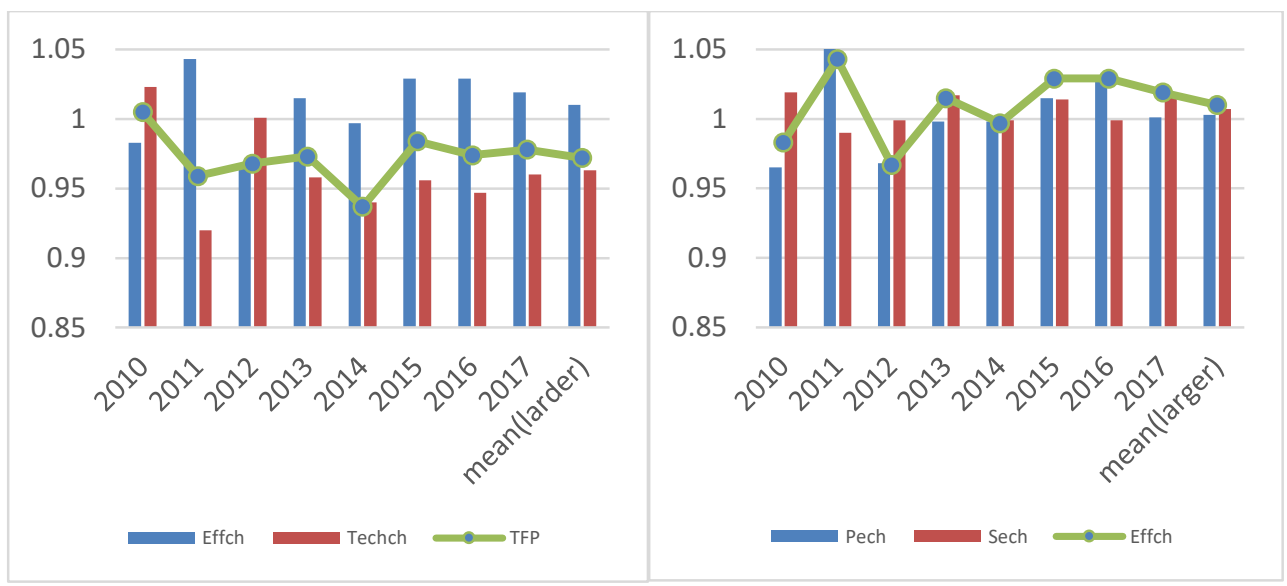

Fig. 4 Dynamic evaluation, technical efficiency and decomposition of larger hospitals

In order to further lead to the analysis of the technical efficiency change, according to Effch=PEch $\times$ SEch, the technical efficiency change is decomposed into pure technical efficiency change and scale efficiency change ${ }^{[10]}$. See Fig. 4. It can be seen from the figure that the change of technical efficiency is basically consistent with the trend of pure technical efficiency change, and the change of pure technical efficiency is the main reason for the change of technical efficiency. From the above analysis, it is known that the main cause of the change in the productivity index is the

change in technology, followed by the change in pure technical efficiency.
For the primary hospitals, the average value of various efficiency indicators during the study period was less than 1 , indicating that the operation level of primary hospitals nationwide is declining. Except for 2009-2010, 2012-2013 and 2014-2015, the productivity index is greater than 1, and the rest of the years are less than 1. According to the trend of the graph, it can be seen that the technical efficiency change is the main reason, followed by the technological change; the contribution rate of technological progress is far less than the growth rate of the output of the primary hospital.

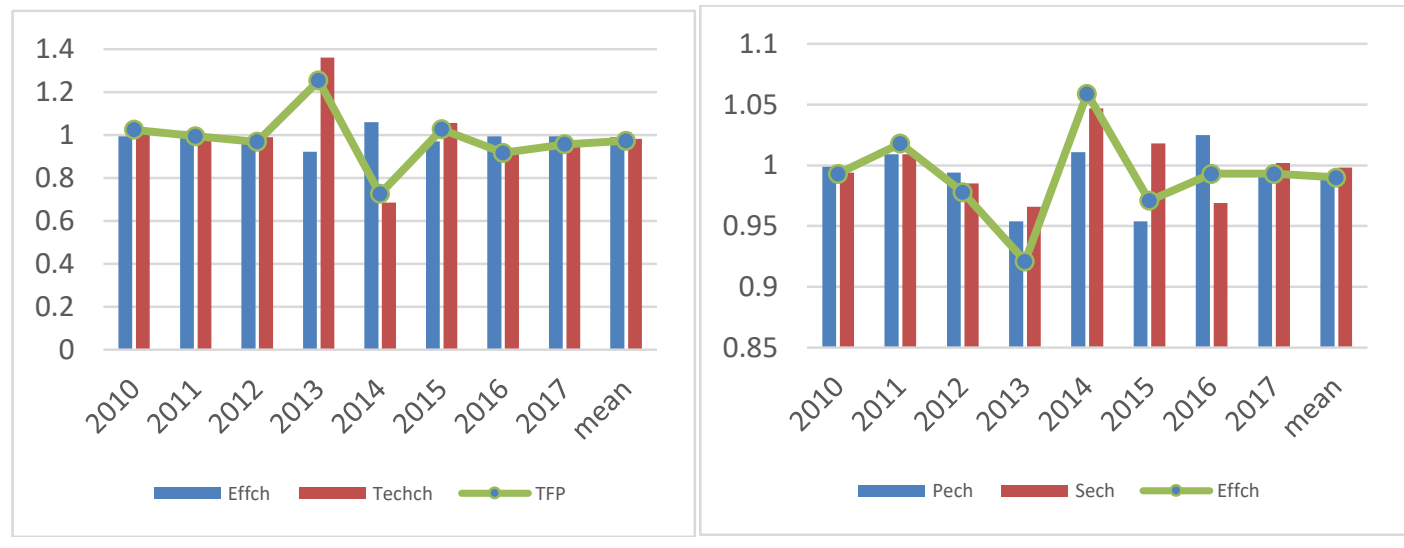

Fig. 5 Dynamic evaluation, technical efficiency and decomposition of primary hospitals 
The reason is that the scale efficiency is found to be the cause of the change of technical efficiency. Therefore, the scale of China's primary hospitals can still not adapt to the demand for outpatient volume, which will be one of the important factors hindering the effect of grading diagnosis and treatment. The reasons for restricting the improvement of production efficiency in primary hospitals are the shortage of primary medical resources, the backwardness of the medical practitioners, and the serious insufficiency of technical application level in small primary hospitals graphically.

\section{V.CONCLUSION}

1) The results of grading diagnosis and treatment in medical and health institutions in China are not good, and the regional differences are significant. Compared with medical and health institutions at the same level, large hospitals in the eastern region and grassroots hospitals nationwide are significantly lower. Judging from the realization of the goal of grading diagnosis and treatment, the outflow effect of outpatients in medical institutions is not good. The $80.65 \%$ (25/31) large hospitals in the country have blind expansion, and the problem of surplus health technicians has led to excessive concentration of resources in large hospitals. In terms of common diseases and frequently-occurring diseases, there is excessive competition between large hospitals and grass-roots hospitals. In addition, the comprehensive efficiency of primary hospitals in China is higher than that of large hospitals, but it shows a downward trend. The insufficient number of beds and health technicians are the key indicators hindering the improvement of the curative effect of grading diagnosis.

2) The total factor productivity of large hospitals is lower than that of primary hospitals. The change of productivity is mainly affected by technological changes. The change of pure technical efficiency is the main reason for the change of technical efficiency. The output level of technological innovation of large hospitals cannot meet the requirements of current grading diagnosis and treatment.

3) The change in productivity is mainly affected by technological changes ${ }^{[11]}$. The medical technology in primary hospitals is backward and there is a lack of various technical personnel such as general practitioners. The core problem is that the degree of technological progress does not match the current medical needs. In addition, after the efficiency of decomposition technology changes it is found that scale efficiency is the cause of changes in technical efficiency. In general, the lack of facilities in primary hospitals and the lack of talents are the main reasons for restricting the improvement of efficiency of grading diagnosis.

\section{REFERENCES}

[1] Chen Zhixian et al, The Theoretical Framework for the Evaluation of the Effect of Grading Diagnosis and Treatment. Health Economics Research,2017(12):25-27.
[2] Yao Jinwen et al,. Hierarchical Diagnosis and Treatment Pilot Model and Effects Evaluation of Huining County of Gansu Province.Chinese genetal practice,2016,19(22):2632-2635.

[3] Zheng Wanhui,Long Chang,Sun Hong, Hierarchical Diagnosis and Treatment Pilot Model and Effects Evaluation of Huining County of Gansu Province. Journal of Shanghai Jiao Tong University(Medical Science),2016,36(12):1789-1795+1803.

[4] Wang Cunhui et al, Study on Operational Efficiency and Influencing Factors of County-level Public Hospitals based on DEA-Tobit Model. Journal of Nanjing Medical University(Social Sciences),2019,19(01):45-49.

[5] Shi Shiwen et al, A Discussion of the Present Situation of Hierarchica Medical System Based on a Perspective of the Return to Scale of Traditional Chinese Medicine Hospital. Chinese Hospital Management ,2016,36(03):1-3

[6] Bai Ge et al, Screening Methods and Empirical Study of Outpatient Who Can Flow from Tertiary Hospitals. Chinese Hospital Management,2017,37(11):1-2

[7] Sun Jian et al, A Study on the Forecast of Primary Health Resources Allocation and Health Services Utilization in China. Smart Healthcare,2017,3(14):27-29.

[8] [1]Chen Yun, Research on Evaluation of Operational Efficiency of Chinese Medicine Hospitals in China under the Background of "New Medical Reform". Chinese Journal of Health Statistics, 2019,36(01):75-77+80

[9] Xu Wenying,Li Chao,Wu Ming,The Empirical Analysis of the Health Care Resource Efficiency from the Hospital Competitive Strategy Model in China. Business Management,2011,33(08):156-161.

[10] Su Qin,Li Yongfei,Zhang Yan, Logistics Industry and Manufacturing Status and Linkage Analysis of Shaanxi Province. Statistics \& Information Forun,2011,26(12):89-96

[11] Che Lianhong,Cheng Xiaoming, A Dynamic Research on Technical Efficiency of Chinese Township Health Centers. Chinese Health Resources,2011,14(3):174-176. 
